\title{
Clinical Evaluation of a Colored Compomer in Primary Molars
}

\author{
Aylin Akbay Oba ${ }^{a}$ Işıl Şaroğlu Sönmez ${ }^{a}$ Şaziye Sari ${ }^{b}$ \\ Department of Pediatric Dentistry, Faculty of Dentistry, ${ }^{a}$ University of Kırıkkale, Kırıkkale and \\ bUniversity of Ankara, Ankara, Turkey
}

\section{Key Words}

Class II restorations $\cdot$ Colored compomer $\cdot$ Primary molars

\begin{abstract}
Objective: The purpose of this study was to evaluate the clinical performance of a new colored compomer material, Twinky Star, in primary molars. Subjects and Methods: Eighty class II restorations were placed in a total of 36 subjects and the clinical success of the restorations was evaluated after 12 months based on modified US Public Health Services criteria. Results: The failure rate of the restorations was 3.9\% (3 out of 77) and the clinical success of the restorations, measured by anatomic form, marginal integrity, marginal discoloration, surface texture, maintenance of interproximal contact and secondary caries, was acceptable. Conclusion: The clinical success of the colored compomer material, Twinky Star, indicates that it could be a good alternative to tooth colored compomers.
\end{abstract}

Copyright $\odot 2008$ S. Karger AG, Basel

\section{Introduction}

Polyacid-modified resin composites, commonly called compomers, were developed as direct esthetic restorative materials that combine the desirable properties of lightcuring composites with those of fluoride-releasing glassionomer cements $[1,2]$. Compomers demonstrate improved physical, chemical and mechanical properties, and better wear resistance than traditional, reinforced and resin-modified glass ionomers, but they are still inferior in these properties compared to conventional resin composites. Nevertheless, compomers were introduced for the treatment of class I and class II lesions in the primary dentition due to their fluoride-releasing potential, bonding capacity with enamel and dentin without the need for acid etching, and their simple handling properties [1].

Colored compomers have been available for use in the restoration of primary molars for over 3 years. In contrast to conventional polyacid-modified resin composites, they contain a small amount of glitter particles which produce a color effect in shades of red, blue or gold. The filler content is similar to conventional compomers [1, 3].

There are two commercially available colored compomers named MagicFil (Zenith, Englewood, N.J., USA) and Twinky Star (Voco, Cuxhaven, Germany). Twinky Star is a light-cured, colored, radiopaque and fluoridereleasing compomer filling system made specifically to be used in primary teeth.

Short-term laboratory studies offer some information about the physical properties of new materials. Nevertheless, long-term clinical studies complement these studies and provide further information regarding the performance of these materials over an acceptable time period [4]. This newly developed colored compomer has not yet been tested clinically. For this reason, the aim of this study was to evaluate the clinical performance of Twinky Star in primary molars over a 12-month period.

\section{KARGER \\ Fax +4161306 1234 \\ E-Mail karger@karger.ch}

www.karger.com
(C) 2008 S. Karger AG, Basel

1011-7571/09/0181-0031\$26.00/0

Accessible online at:

www.karger.com/mpp
Issıl Saroğlu Sönmez

Kırıkkale Üniversitesi, Diş Hekimliği Fakültesi

Pedodonti ABD

Kirıkkale (Turkey)

Tel. +90 31822436 18, Fax +90 31822469 07, E-Mail isilsaroglu@yahoo.com 
Table 1. US Public Health Service modified Ryge criteria

Anatomic form

1 Restoration is continuous with existing anatomical form

2 Restoration is discontinuous with existing anatomical form, but missing material is not sufficient to expose dentin

3 Sufficient material missing to expose dentin

Marginal integrity

1 Explorer does not catch and/or no crevice is visible

2 Explorer catches and crevice is visible, but no exposure of dentin and restoration is not mobile

3 Explorer penetrates crevice, defect extends to dentino-enamel junction

4 Restoration is fractured, mobile or missing, either in part or in toto

Marginal discoloration

1 No visual evidence of marginal discoloration

2 Marginal discoloration has not yet penetrated in pulpal direction

3 Marginal discoloration has penetrated in pulpal direction

Surface texture

1 Surface texture similar to polished enamel

2 Surface texture gritty (similar to white stone)

3 Coarse surface pitting

Maintenance of interproximal contact

1 Proximal contact is present

2 Proximal contact is light but present

3 No proximal contact

0 No adjacent proximal surface

Recurrent caries

1 No caries present

2 Caries present associated with restoration

Postoperative sensitivity

1 No known sensitivity to hot, cold and biting stimuli

2 Moderate sensitivity to hot, cold and biting stimuli

3 Severe sensitivity; replacement of restoration required

\section{Subjects and Methods}

A total of 36 subjects, 18 boys and 18 girls, with a mean age of 7.3 years (range 6-9 years) were chosen among patients attending the Department of Pediatric Dentistry, School of Dentistry, University of Kirıkkale, Turkey. The purpose and clinical procedures of the study were fully explained to the parents, and consent forms were completed and signed. This study was approved by the Institution's Ethics Board. Eighty restorations were placed by two experienced pediatric dentists (A.A.O. and I.Ş.S.). Teeth were selected based on the following criteria: radiographic (bitewing radiograph) evidence of class II caries; proximal contact with adjacent healthy or restored teeth; no indication for pulp therapy or other restorative treatment; no undermining of cusps by caries; no caries lesions extending below the gingival margin of the cavity preparation, and a predicted time to tooth exfoliation of at least
2 years. The children were given oral hygiene instructions and additional dental treatment during the study period.

The teeth eligible for the trial were prepared with a high-speed bur - under local analgesia if needed -, rinsed and dried. Approximal cavities were prepared according to minimally invasive preparation rules; preventive extension was thus avoided. After preparation, a matrix (Tofflemire, Fort Collins, Colo., USA) and wooden wedge (Platon, Arma, Turkey) were inserted. No liner was used. Isolation was achieved with cotton wool rolls and a saliva ejector. A self-etching bonding system was used (Futurabond NR, Voco) to bond the enamel and compomer material according to the manufacturer's instructions. Twinky Star restorations were placed according to the manufacturer's instructions in horizontal layers not exceeding a thickness of $2 \mathrm{~mm}$ to allow proper polymerization of the material; each layer was polymerized for $40 \mathrm{~s}$. Occlusion was checked with an articulating paper and as appropriate. The restorations were finished using diamond finishing burs and disks (3M ESPE, St. Paul, Minn., USA).

Direct evaluations of the restorations were undertaken by one investigator (I.Ş.S.). During the follow-up evaluations, the clinical success of the restorations was scored based on modified US Public Health Services criteria [5] (table 1). Evaluations were carried out at baseline and after 12 months under normal clinical conditions with a dental operating light, a mouth mirror and a dental explorer. Score 1 indicates a clinically ideal situation; score 2 (apart from caries) indicates a clinically acceptable situation; score 3 indicates a clinically unacceptable situation, which usually requires replacement of the restoration, and score 4 indicates a clinically unacceptable situation because of fracture, mobility or loss of the restoration, which makes it necessary to replace it.

\section{Results}

The distribution of the treated teeth according to the jaw and number of teeth is presented in table 2. The color preferences of the children are listed in table 3 . The preferred color for girls $(16 ; 36.36 \%)$ was pink, whereas boys preferred lemon $(13 ; 36 \%)$.

A total of 77 teeth in 34 patients were followed up for 12 months. The results of the assessment of the clinical performance of the restorations are given in table 4 . After 12 months, only 3 restorations (3.9\%) had to be replaced due to marginal ridge fractures of the restorations. Seventy-four (96.1\%) restorations were still in function after 12 months. Of the 74 restorations, $2.6 \%$ showed loss of marginal integrity but without exposure of dentin and 1 restoration showed discontinuity with the existing anatomical form. Only 2 silver-colored restorations showed marginal discoloration, scored as 2 , and there was no discoloration in the remaining colored restorations. No further treatment was indicated for these teeth because there was no loss of tooth structure and the discoloration was superficial. 
None of the patients complained of postoperative sensitivity. Apart from 1 (1.29\%) fractured restoration, no secondary caries was observed in the other 76 (98.7\%) restorations after 12 months.

\section{Discussion}

Polyacid-modified resin composites have been introduced as materials for the conservative restoration of primary teeth based on the results of clinical trials $[1,6,7]$. Although the results of clinical studies may not express the clinical performance of restorations placed by general practitioners, these studies show the potential of a restorative material for specific clinical applications and reveal the main causes of restoration failures [8]. The present study was undertaken to investigate the clinical performance of the colored compomer, Twinky Star, in class II restorations of primary teeth.

The results of the present study show that the failure rate of the restorations was 3.9\% (3 out of 77) and the clinical success of the restorations, as measured by anatomic form, marginal integrity, marginal discoloration, surface texture, maintenance of interproximal contact and secondary caries, is acceptable (table 4).

Compomer and composite restorations appear to be as successful as glass ionomer, resin-modified glass ionomer, and amalgam for class II restorations in primary molars over the time interval studied, and offer an excellent and esthetic alternative $[9,10]$. One advantage of compomers is their ease of manipulation. Their consistency makes it easy to apply and contour them without sticking. Less time is therefore required for finishing and final polishing. These features are especially beneficial when treating children $[1,11]$. Clinical studies have shown that commercially available compomers have high clinical success rates which are comparable to amalgam, and this makes them a suitable alternative to amalgam for restoring primary teeth in children [12-14].

Other studies have shown that, when different compomer materials were used, the clinical failure rate ranged from 0 to $42 \%$ [10-13, 15, 16]. Papagiannoulis et al. [17] reported that the highest retention rate with Dyract restorations was $100 \%$. In contrast to the present study, the cavity design in that study followed Black's principles, which may explain the high retention rates obtained.

The finding of $1.3 \%$ recurrent caries at the 12 -month follow-up is similar to that of Peters et al. [18], who reported a $1 \%$ incidence of recurrent caries after 1 year with Dyract material, and Kavvadia et al. [13], who reported
Table 2. Distribution of the teeth according to jaw and number of teeth

\begin{tabular}{llll}
\hline & $\begin{array}{l}\text { Primary } \\
\text { first molar }\end{array}$ & $\begin{array}{l}\text { Primary } \\
\text { second molar }\end{array}$ & Total \\
\hline Upper jaw & 13 & 19 & 32 \\
Lower jaw & 23 & 25 & 48 \\
\hline Total & 36 & 44 & 80 \\
\hline
\end{tabular}

Table 3. Distribution of the subjects' color preferences

\begin{tabular}{lccc}
\hline Color & Girls & Boys & Total \\
\hline Pink & $16(36.36)$ & - & 16 \\
Lemon & $7(15.9)$ & $13(36.1)$ & 20 \\
Blue & $2(4.54)$ & $11(30.55)$ & 13 \\
Green & $1(2.27)$ & $4(11.11)$ & 5 \\
Gold & $7(15.9)$ & $1(2.77)$ & 8 \\
Silver & $11(25)$ & $7(19.44)$ & 18 \\
Orange & - & - & - \\
\hline Total & $44(100)$ & $36(100)$ & 80 \\
\hline
\end{tabular}

Figures in parentheses are percentages.

Table 4. Clinical assessment of the restoration after 12 months

\begin{tabular}{lllll}
\hline Criteria & \multicolumn{2}{l}{ Score } \\
\cline { 2 - 5 } & 1 & 2 & 3 & 4 \\
\hline Anatomic form & $73(94.8)$ & $1(1.3)$ & $3(3.9)$ & 0 \\
Marginal integrity & $72(93.5)$ & $2(2.6)$ & 0 & $3(3.9)$ \\
Marginal discoloration & $75(97.4)$ & $2(2.6)$ & 0 & 0 \\
Surface texture & $77(100)$ & 0 & 0 & 0 \\
Interproximal contact & $74(96.1)$ & $1(1.3)$ & $2(2.6)$ & 0 \\
Recurrent caries & $76(98.7)$ & $1(1.3)$ & 0 & 0 \\
Postoperative sensitivity & $77(100)$ & 0 & 0 & 0 \\
\hline
\end{tabular}

Figures in parentheses are percentages.

1.7\% caries with F2000 restorations. However, Papagiannoulis et al. [17] reported a secondary caries rate of $6 \%$ at cervical margins 24 months after Dyract restorations. The compomer material tested in our study showed a lower incidence of secondary caries than with amalgams (9\%), cermet cements (9\%), conventional glass ion- 
omers (4\%) and resin composites (6\%) tested in other studies $[8,19]$.

Our study has shown that Twinky Star could be used as an alternative to tooth-colored compomers because of its high clinical success after 1 year. It has been reported that young patients who are allowed to choose the color of their restorations are more likely to accept the idea of treatment. The success of the treatment is aided even further by the dentist's explanation to the children that the fillings will continue to look good as long as the patient maintains them properly [20].

These 1-year restorations were not compared with others in a split-mouth design. In a review of tooth-col- ored restorations in primary molars, Toh and Messer [21] stated that prospective randomized clinical trials should be of at least 5 years' duration for correctly determining the success rate of class II restorations in primary molars. So the results of our study should be viewed as promising 1-year data.

\section{Conclusion}

The colored compomer material, Twinky Star, showed promising results in this 12-month follow-up study of class II restorations in primary molars.

\section{References}

$>1$ Kramer N, Frankenberger R: Compomers in restorative therapy of children: a literature review. Int J Paediatr Dent 2007;17:2-9.

$>2$ Luo Y, Lo ECM, Fang DTS, Wei SHY: Clinical evaluation of polyacid-modified resin composite posterior restorations: one-year results. Quintessence Int 2000;31:630-636.

-3 Croll TP: MagicFil: A colourful kiddie compomer. Compend Contin Educ Dent 2002; 23:1044-1048.

4 Knibbs PJ: Methods of clinical evaluation of dental restorative materials. J Oral Rehabil 1997;24:109-123.

5 Ryge G: Clinical criteria. Int Dent J 1980;30: 347-358.

$\checkmark 6$ Welbury RR, Shaw AJ, Murray JJ, Gordon $\mathrm{PH}, \mathrm{McC}$ abe JF: Clinical evaluation of paired compomer and glass ionomer restorations in primary molars: final results after 42 months. Br Dent J 2000;189:93-97.

7 Lutz F: State of art of tooth-colored restorations. Oper Dent 1996;21:237-248.

$>8$ Kilpatrick NM: Durability of restorations in primary molars. J Dent 1992;21:67-73.

$>9$ Gross LC, Griffen AL, Casamassimo PS: Compomers as class II restorations in primary molars. Pediatr Dent 2001;23:24-27.
10 Turgut MD, Tekçiçek M, Ölmez S: Clinical evaluation of a polyacid-modified resin composite under different conditioning methods in primary teeth. Oper Dent 2004;29:515523.

11 Hse KMY, Wei SHY: Clinical evaluation of compomer in primary teeth: 1-year results. J Am Dent Assoc 1997;128:1088-1096.

12 Duggal MS, Toumba KJ, Sharma NK: Clinical performance of a compomer and amalgam for the interproximal restoration of primary molars: a 24-month evaluation. $\mathrm{Br}$ Dent J 2002;193:339-342.

13 Kavvadia K, Kakaboura A, Vanderas AP, Papagiannoulis L: Clinical evaluation of a compomer and an amalgam in primary teeth class II restorations: a 2-year comparative study. Pediatr Dent 2004;26:245-250.

14 Donly KJ, Segura A, Kanellis M, Erickson RL: Clinical performance and caries inhibition of resin modified glass ionomer cement and amalgam restorations. J Am Dent Assoc 1999;130:1459-1466.

15 Anderson-Wenckert IE, Folkesson UH, Van Dijken JWV: Durability of a polyacid-modified composite resin (compomer) in primary molars. A multicenter study. Acta Odont Scand 1997;55:255-260.
16 Pascon FM, Kantovitz KR, Caldo-Teixeria AS, Borges AFS, Silva TN, Puppin-Rontani RM, Garcia-Godoy F: Clinical evaluation of composite and compomer restorations in primary teeth: 24-month results. J Dent 2006;34:381-388.

17 Papagiannoulis L, Kakaboura A, Pantaleon F, Kavvadia K: Clinical evaluation of a polyacid-modified resin composite (compomer) in class II restorations of primary teeth: a two-year follow-up study. Pediatr Dent 1999; 21:232-235.

18 Peters T, Roeters J, Frankenmolen F: Clinical evaluation of Dyract in primary molars: 1year results. Am J Dent 1996;9:83-87.

19 Barr-Agholme M, Oden A, Dahllof G, Modeer T: A two-year clinical study of lightcured composite and amalgam restorations in primary molars. Dental Mater 1991;7: 230-233.

20 Croll TP, Helpin ML, Donly KJ: Multi-colored dual-cured compomer. Pediatr Dent 2004;26:273-276.

21 Toh SL, Messer LB: Evidence-based assessment of tooth-colored restorations in proximal lesions of primary molars. Pediatr Dent 2007;29:8-15. 